\section{Kidney \\ Blood Pressure Research}

Kidney Blood Press Res 2012;36:344-354

\begin{tabular}{l|l}
\hline DOI: $10.1159 / 000343392$ & (c) 2012 S. Karger AG, Basel
\end{tabular}

www.karger.com $/ \mathrm{kbr}$

344

Original Paper

\title{
Neutrophil Gelatinase-Associated Lipocalin (NGAL) in Chronic Cardiorenal Failure is Correlated with Endogenous Erythropoietin Levels and Decreases in Response to Low- Dose Erythropoietin Treatment
}

Mireille E. Emans ${ }^{a} \quad$ Branko Braam ${ }^{b} \quad$ Adry Diepenbroek ${ }^{c} \quad$ Karien van der Putten ${ }^{d}$ Maarten J. Cramera Jos P.M. Wielders ${ }^{\mathrm{e}}$ Dorine W. Swinkels ${ }^{f}$

Pieter A. Doevendansa,g Carlo A. Gaillardc,h

${ }^{a}$ Dept. of Cardiology, University Medical Centre Utrecht, the Netherlands, ${ }^{b}$ Division of Nephrology and Immunology, Dept. Medicine, University of Alberta, Edmonton, Canada, 'Dept. of Internal Medicine, Meander Medical Centre Amersfoort, the Netherlands, ${ }^{d}$ Dept. of Nephrology, Leiden University Medical Center, the Netherlands, ${ }^{e}$ Dept. of Clinical Chemistry, Meander Medical Centre Amersfoort, the Netherlands, fLaboratory of Genetic, Endocrine and Metabolic Diseases, Dept. of Laboratory Medicine, Radboud University Medical Centre, Nijmegen, the Netherlands, IInteruniversitary Cardiological Institute (ICIN), the Netherlands, 'Department of Nephrology, VU University Medical Centre, Amsterdam, the Netherlands

\section{Key Words}

Cardiorenal syndrome - NGAL • Erythropoietin - Iron homeostasis • Biomarkers • Chronic kidney disease $\cdot$ Chronic heart failure

\begin{abstract}
Background: Neutrophil-gelatinase associated lipocalin (NGAL), a tubular injury marker, is associated with iron metabolism in hemodialysis patients. We investigated whether serum NGAL levels reflect iron metabolism in combined chronic heart failure and chronic kidney disease (CHF/CKD) and whether treatment with low-dose erythropoietin stimulating agent (ESA) modulates NGAL levels. Methods: In the EPOCARES trial (ClinTrialsNCT00356733) serum NGAL, hepcidin-25, transferrin saturation (TSAT), reticulocyte hemoglobin content (Ret-He) and endogenous erythropoietin (EPO) levels were measured. Results: Baseline serum NGAL levels correlated with cystatin $C(r=0.767, p<0.001)$ and baseline EPO levels $(r=-0.395, p=0.003)$. There was no correlation with baseline TSAT, Ret-He, and hepcidin-25 levels. After two weeks, NGAL levels decreased in the ESA-group $(p=0.02)$, while there was no change in the no-ESA group $(p=0.62)$. The magnitude in NGAL decrease in the ESA-group correlated with baseline
\end{abstract}




\section{Kidney Blood Pressure Research}

Kidney Blood Press Res 2012;36:344-354

\begin{tabular}{l|l}
\hline DOI: $10.1159 / 000343392$ & (C) 2012 S. Karger AG, Basel
\end{tabular}

Published online: December 12, 2012

www.karger.com/kbr

Emans/Braam/Diepenbroek/van der Putten/Cramer/Wielders/Swinkels/Doevendans/ Gaillard: NGAL Decreases in Response to ESA in Chronic Cardiorenal Failure

EPO levels $(r=0.431, p=0.01)$. Conclusions: In contrast to in HD patients, in combined CKD/ $\mathrm{CHF}$, serum NGAL levels did not correlate with iron metabolism, hence NGAL might reflect tubular damage in these patients. NGAL levels inversely correlated with baseline EPO levels and decreased in response to short-term ESA treatment, which might reflect an effect of ESA on tubular damage. These findings need to be confirmed and alternative explanations should be evaluated.

Copyright $(2012$ S. Karger AG, Basel

\section{Introduction}

Neutrophil-gelatinase associated lipocalin (NGAL or lipocalin-2), a 25kDa protein of the lipocalin family, acts as a natural bacteriostatic agent by interfering with bacterial iron uptake and also increases in response to inflammation. In the setting of acute renal tubular injury, human serum NGAL levels increase 7 to 16-fold and urinary NGAL levels increase 25100 fold [1]. Consequently, NGAL has been proposed as a biomarker for tubular damage to detect acute kidney injury at an early stage in various conditions [2-4]. However, NGAL has also been shown to be elevated in chronic conditions, such as chronic kidney disease (CKD) $[5,6]$ and chronic heart failure (CHF) [7], presumably reflecting chronic damage to tubular cells, irrespective of the glomerular filtration rate $[8,9]$.

In addition, NGAL levels might also reflect iron metabolism since the NGAL pathway acts as an alternative to the transferrin-mediated iron delivery pathway by cytoplasmic iron delivery into target cells [10]. Recently, Bolignano et al. and Malyszko et al. suggested that low NGAL levels in hemodialysis patients reflect reduced iron availability and transport; lower NGAL levels were associated with lower transferrin saturation (TSAT), lower ferritin levels and higher hepcidin levels [11-13].

Thus, NGAL levels might reflect inflammation, tubular damage or reduced iron availability. Iron deficiency plays an important role in the pathophysiology of CKD and CHF [14] and is related to a reduced quality of life and increased mortality [15]. In combined CHF/ CKD, it is unknown whether NGAL reflects iron metabolism or tubular damage. Since ESA treatment induces increased iron utilization and reduces hepcidin one could hypothesize that during ESA treatment NGAL levels increase $[16,17]$. Therefore, we investigated the hypothesis that (1) serum NGAL levels reflect iron availability in anemic patients with combined chronic heart and kidney failure and (2) that ESA treatment increases serum NGAL levels in accordance with its effect on hepcidin. To this end we measured NGAL and assessed markers of inflammation and iron metabolism including transferrin saturation (TSAT), reticulocyte hemoglobin content (Ret-He) and hepcidin-25 levels, using a mass spectrometry based assay, in the EPOCARES study.

\section{Materials and Methods}

\section{Study design and patients}

The study design of the EPOCARES study (ClinicalTrials.gov number NCT 00356733) has been published elsewhere [18]. In short, the EPOCARES study is an open-label, prospective, randomized trial, in which patients with CHF, CKD (estimated creatinine clearance (eCrCl) by Cockroft-Gault equation of 20-70 $\mathrm{ml} / \mathrm{min}$ ) and mild anemia (hemoglobin 10.3-12.6 g/dL for men and 10.3-11.9 g/dL for women) are included to test the erythropoietic and non-erythropoietic responses to low-dose ESA treatment. Exclusion criteria, amongst others, were ESA therapy within 6 months, bleeding, chronic inflammatory disease or malignancy. Hemoglobin $(\mathrm{Hb})$ level for inclusion was measured after at least four weeks of oral iron supplementation, if tolerated. The diagnostic criteria for CHF were those recommended by the European Society of Cardiology guidelines [19]. Patients with heart failure with reduced left ventricular ejection fraction as well as patients with preserved left ventricular ejection fraction were included [20]. 


\section{Kidney \\ Blood Pressure Research}

Kidney Blood Press Res 2012;36:344-354

\begin{tabular}{l|l}
\hline DOI: $10.1159 / 000343392$ & (c) 2012 S. Karger AG, Basel
\end{tabular}

Published online: December 12, 2012

www.karger.com/kbr

Emans/Braam/Diepenbroek/van der Putten/Cramer/Wielders/Swinkels/Doevendans/ Gaillard: NGAL Decreases in Response to ESA in Chronic Cardiorenal Failure

The subjects were randomized into 3 groups. The first two groups received a fixed dose of $50 \mathrm{IU} / \mathrm{kg}$ per week of ESA (Neorecormon; Roche Pharmaceuticals), After two weeks, the Hb level was let to increase to a maximum of $13.7 \mathrm{~g} / \mathrm{dL}$ for men and $13.4 \mathrm{~g} / \mathrm{dL}$ for women in one group (ESA-Hb-rise group) whereas in the other group the $\mathrm{Hb}$ levels were maintained at baseline level for 26 weeks by sequential blood withdrawal to a maximum of $250 \mathrm{~mL}$ per 2 weeks (ESA-Hb-stable group). The third group, the control group, did not receive ESA (the no-ESA group). In addition, a group of 25 healthy, age- and sex-matched controls were recruited for comparison of NGAL levels. The Medical-Ethical Committee approved the protocol of the study and informed consent was obtained from all subjects. Procedures were in accordance with the Helsinki Declaration and all patients gave written consent.

\section{Biomarker analysis}

All blood samples were drawn between 8 and 9 a.m. and stored at $-80^{\circ} \mathrm{C}$ until analysis. As a marker of total iron stores, ferritin was determined using a sandwich immunoassay on an Acces ${ }^{\circledR} 2$ immunoanalyzer within a Dx automated system from Beckman Coulter (Brea, CA). Functional iron availability was determined by measuring transferrin saturation (TSAT), soluble transferrin receptor (sTfR) and reticulocyte hemoglobin content (Ret-He). TSAT was calculated from serum iron and transferrin estimates obtained with standard methods on a Beckman Coulter Dx. sTfR assay was performed with an immunoassay on a BNProSpec nephelometer from Siemens (Marburg, Germany). Ret-He was performed using flow cytometric analysis with Ret-Search (II) ${ }^{\circledR}$ dye on a Sysmex XE-2100 hematology analyzer (Toa Medical, Kobe, Japan).

Serum hepcidin-25 measurements were performed by a combination of weak cation exchange chromatography and time-of-flight mass spectrometry (TOF MS) [21]. An internal standard (synthetic hepcidin-24; Peptide International Inc.) was used for quantification [22]. Peptide spectra were generated on a Microflex LT matrix-enhanced laser desorption/ionisation TOF MS platform (Bruker Daltonics). Serum hepcidin-25 concentrations were expressed as nmol/l. The lower limit of detection (LLOD) of this method was $0.5 \mathrm{nM}$; ranges for the coefficients of variation were 2.2-3.7\% (intra-run) and 3.9-9.1\% (inter-run). The median reference level of serum hepcidin- 25 is $4.5 \mathrm{nM}$ for men, $2.0 \mathrm{nM}$ for premenopausal women, and 4.9 $\mathrm{nM}$ for postmenopausal women. The reference levels for the WCX-TOF MS method were derived from those of a competitive ELISA method [23], based on the regression line between the data of both methods on the same samples [21].

Serum NGAL levels were measured on the Triage ${ }^{\circledR}$ NGAL test (Alere Inc. San Diego, CA, USA), an immunoassay in a single-use plastic cartridge that contains a fluorescently labeled monoclonal antibody against NGAL labeled with a fluorescent dye and NGAL. Measurements of NGAL concentration in the range from 60 to $1300 \mathrm{ng} / \mathrm{ml}$. Calibration information is relayed to the meter via a lot-specific EPROM chip [4].

Assessment of changes in hemoglobin levels in time

Two study groups received similar dosages of ESA treatment during the study period (together the ESA group). After two weeks the ESA group was split into the ESA-Hb-stable and the ESA-Hb-rise group. In the ESA-Hb-stable group the $\mathrm{Hb}$ levels were kept at baseline level using phlebotomies. To assess the necessity of a phlebotomy, a preceding increase in $\mathrm{Hb}$ was required, for which the $\mathrm{Hb}$ levels were measured every 2 weeks, which makes comparison of single time-point measurements unreliable. We therefore assessed the $\mathrm{Hb}$ response by calculating the area under the curve for $\mathrm{Hb}$ change in time (Hb AUC) in the groups. Furthermore, the $\mathrm{Hb}$ AUC is more informative to asses the $\mathrm{Hb}$ response to ESA treatment and its clinical significance on end points [24]. The Hb AUC was calculated by linear trapezoidal integration, in which the total area under the $\mathrm{Hb}$ change versus time curve is obtained by summation of each individual area between two consecutive time points, as extensively described elsewhere [24]. The Hb AUC was based on monthly $\mathrm{Hb}$ measurements in all patients.

\section{Statistical analysis}

Data are presented as means \pm standard deviation (SD) for normally distributed variables and median with inter-quartile ranges (IQR) for non-normally distributed variables. Normality of data was evaluated using the Kolmogorov-Smirnov test. Non-normally distributed variables were log transformed, after which normality was tested again. Differences between groups were compared with the unpaired student's t-test, Mann-Whitney U test or $\chi^{2}$-test where appropriate. Paired data were compared with the paired student's t-test using a Bonferroni adjusted alpha level. Pearson correlation or Spearman's rho were used for bivariate 


\section{Kidney \\ Blood Pressure Research}

Kidney Blood Press Res 2012;36:344-354

\begin{tabular}{l|l}
\hline DOI: $10.1159 / 000343392$ & C 2012 S. Karger AG, Basel
\end{tabular}

Published online: December 12, 2012

www.karger.com/kbr

Emans/Braam/Diepenbroek/van der Putten/Cramer/Wielders/Swinkels/Doevendans/ Gaillard: NGAL Decreases in Response to ESA in Chronic Cardiorenal Failure

Table 1: Baseline characteristics

\begin{tabular}{lccc}
\hline Characteristic & ESA, $\mathrm{n}=37$ & No ESA, $\mathrm{n}=19$ & $\mathrm{p}$ - value \\
\hline Age, years & $76[70-81]$ & $72[66-77]$ & 0.52 \\
Male sex, $\mathrm{n}(\%)$ & $23(62.2)$ & $14(73.7)$ & 0.39 \\
BMI $\left(\mathrm{kg} / \mathrm{m}^{2}\right)$ & $26.1 \pm 4.2$ & $27.4 \pm 4.2$ & 0.68 \\
Diabetes, $\mathrm{n}(\%)$ & $12(32.4)$ & $7(36.8)$ & 0.74 \\
Hypertension, $\mathrm{n}(\%)$ & $27(80.0)$ & $16(84.2)$ & 0.35 \\
NGAL (ng/mL) & $189[133-265]$ & $238[129-313]$ & 0.86 \\
NT-proBNP (pg/mL) & $1400[744-2631]$ & $1680[659-2610]$ & 0.81 \\
LVEF (\%) & $42.1 \pm 9.1$ & $44.1 \pm 12.3$ & 0.22 \\
hs-CRP (mg/L) & $5.4[1.3-10.9]$ & $4.3[1.7-6.9]$ & 0.55 \\
RAS inhibitor, n (\%) & $35(94.6)$ & $19(100.0)$ & 0.30 \\
Hemoglobin (g/dL) & $11.7 \pm 0.95$ & $11.8 \pm 0.79$ & 0.74 \\
Hematocrit (\%) & $0.35 \pm 0.031$ & $0.35 \pm 0.026$ & 0.96 \\
Ferritin (ng/mL) & $130[75-209]$ & $128[76-164]$ & 0.43 \\
Transferrin saturation (\%) & $20[15-25]$ & $20[18-29]$ & 0.76 \\
Erythropoietin (IU/L) & $13[9-16]$ & $15[5-17]$ & 0.95 \\
\hline
\end{tabular}

Mean \pm standard deviation or median [interquartile range] are shown. Abbreviations: BMI, body mass index; NGAL, neutrophil gelatinase-associated lipocalin; NTproBNP, N-terminal pro-brain natriuretic peptide; LVEF, left ventricular ejection fraction; hs-CRP, high sensitivity C-reactive protein; RAS inhibitor, renin-angiotensin-system inhibitor

correlations (resp. normally and non-normally distributed variables). The one-way ANOVA was used for multiple group comparisons. Multivariable linear regression models with stepwise forward selection process were performed. Differences were considered significant when $\mathrm{P}<0.05$, two-sided. For statistical analyses the Statistical Package for Social Sciences (IBM, Chicago, Illinois, USA) version 18 for Mac was used.

\section{Results}

\section{Baseline characteristics}

The study population of the EPOCARES study comprised of 62 patients, of whom 5 patients withdrew their informed consent and 1 patient was withdrawn because of malignancy. Baseline characteristics of the remaining 56 patients are displayed in Table 1, divided by ESA group and no-ESA group. All patients had CKD, CHF and were anemic, as shown by the decreased eCrCl, left ventricular ejection fraction (LVEF), Hb-levels and the higher NT-proBNP levels. Despite oral iron supplementation, TSAT levels were low in some patients ( $<20 \%$ in 26 of the patients or $<15 \%$ in 8 patients). However, in the 37 patients that received ESA, Ret-He did not decrease, indicating that there was no iron-restricted erythropoiesis. At baseline, there were no differences between the ESA group and the noESA group.

The NGAL levels in the EPOCARES cohort were increased in comparison to healthy ageand sex-matched volunteers (207 [132-287] ng/mL vs. 77 [60-116] ng/mL, $\mathrm{n}=25 ; \mathrm{p}<0.001)$. When divided according to baseline NGAL levels below and above the median (high $\geq 207$ $\mathrm{ng} / \mathrm{mL}$ vs. low $<207 \mathrm{ng} / \mathrm{mL}$ ), patients with high NGAL values had hi gher cystatin C, NTproBNP and interleukin- 6 and lower eCrCl, serum iron and endogenous EPO levels, as shown in Table 2.

Univariate correlations of baseline NGAL and multiple regression analysis

Table 3. shows the univariate correlations with serum NGAL levels at baseline. Serum NGAL levels correlated positively with urea nitrogen, cystatin $\mathrm{C}$ levels and microalbuminuria 


\section{Kidney Blood Pressure Research}

Kidney Blood Press Res 2012;36:344-354

\begin{tabular}{l|l}
\hline DOI: $10.1159 / 000343392$ & (C) 2012 S. Karger AG, Basel
\end{tabular}

Published online: December 12, 2012

www.karger.com/kbr

Emans/Braam/Diepenbroek/van der Putten/Cramer/Wielders/Swinkels/Doevendans/ Gaillard: NGAL Decreases in Response to ESA in Chronic Cardiorenal Failure

Table 2: Baseline variables according to serum NGAL levels below or above median

\begin{tabular}{lccc}
\hline Characteristic & Low NGAL, $\mathrm{n}=28$ & High NGAL, $\mathrm{n}=28$ & $\mathrm{p}$ - value \\
\hline Diabetes, $\mathrm{n}(\%)$ & $10(35.7)$ & $9(32.1)$ & 0.50 \\
Hypertension, $\mathrm{n}(\%)$ & $19(67.9)$ & $24(85.7)$ & 0.10 \\
eCrCl $(\mathrm{ml} / \mathrm{min})$ & $44 \pm 16$ & $30 \pm 10$ & $<\mathbf{0 . 0 0 1}$ \\
Cystatin C (mg/L) & $1.45[1.10-1.68]$ & $2.40[1.87-2.87]$ & $<\mathbf{0 . 0 0 1}$ \\
NT-proBNP (pg/mL) & $1280[531-2139]$ & $1742[894-5115]$ & $\mathbf{0 . 0 2 0}$ \\
hs-CRP (mg/L) & $5.4[1.3-10.9]$ & $4.3[1.7-6.9]$ & 0.21 \\
Interleukin-6 (pg/mL) & $2.8[1.7-4.7]$ & $4.1[2.3-7.2]$ & $\mathbf{0 . 0 4 4}$ \\
Hemoglobin $(\mathrm{g} / \mathrm{dL})$ & $11.8 \pm 0.86$ & $11.8 \pm 0.94$ & 0.74 \\
Serum iron $(\mu \mathrm{mol} / \mathrm{L})$ & $12[10-16]$ & $10[8-14]$ & $\mathbf{0 . 0 2 7}$ \\
Ferritin $(\mathrm{ng} / \mathrm{mL})$ & $133[78-216]$ & $117[75-167]$ & 0.53 \\
Transferrin saturation $(\%)$ & $22[18-26]$ & $18[14-25]$ & 0.19 \\
sTfR (mg/L) & $1.28 \pm 0.36$ & $1.48 \pm 0.55$ & 0.11 \\
Ret-He (fmol) & $1.90 \pm 0.14$ & $1.88 \pm 0.14$ & 0.11 \\
Hepcidin-25 (nM) & $5.4[3.2-7.4]$ & $7.0[4.4-8.8]$ & 0.14 \\
Erythropoietin (IU/L) & $15[12-19]$ & $10[6-15]$ & $\mathbf{0 . 0 0 5}$ \\
\hline
\end{tabular}

Mean \pm standard deviation or median [interquartile range] are shown. Abbreviations: NGAL, neutrophil gelatinase-associated lipocalin; $\mathrm{eCrCl}$, estimated creatinine clearance by Cockroft Gault; NTproBNP, N-terminal pro-brain natriuretic peptide; hs-CRP, high sensitivity C-reactive protein; sTfR, soluble transferrin receptor; Ret-He, reticulocyte hemoglobin content

and negatively with eCrCl. Furthermore, there was a negative correlation between baseline NGAL levels and endogenous EPO levels (Fig 1A). This correlation between endogenous EPO levels and serum NGAL remained significant after adjustment for $\mathrm{eCrCl}$ and cystatin $\mathrm{C}$ (adjusted $\mathrm{r}=-0.358$, $\mathrm{p}=0.008$ ), as for microalbuminuria (adjusted $r=-0.338, p=0.020$ ) and for Hb-levels (adjusted $\mathrm{r}=-0.400, \mathrm{p}=0.003$ ). There was no significant association between serum NGAL levels and age, $\mathrm{Hb}$ levels or with parameters for iron stores and iron availability such as ferritin, TSAT, sTfR and Ret-He. Nor did we find a correlation with hepcidin-25 levels (Fig. 1B) or inflammation.

After multiple regression analysis, stepwise including variables with univariate correlation with NGAL with $\mathrm{p}<0.1$, cystatin $\mathrm{C}$ $(\beta=0.804, p<0.001)$, endogenous EPO levels $(\beta=-0.249, p=0.004)$ and urea $(\beta=0.325$, $\mathrm{p}=0.016)$ were the predictors for baseline serum NGAL levels (explaining 74.0\% of NGAL variations).

\section{Acute response to ESA treatment}

Table 4. shows the effect of 2 weeks ESA treatment versus no treatment on the variables. Hb levels, reticulocytes and STfR
Table 3: Univariate correlations with serum NGAL levels at baseline

\begin{tabular}{|c|c|c|}
\hline \multirow[t]{2}{*}{ Variable } & \multicolumn{2}{|c|}{ NGAL } \\
\hline & $\mathrm{r}$ & p-value \\
\hline Age & -0.184 & 0.18 \\
\hline Hemoglobin & -0.112 & 0.41 \\
\hline NT-proBNP & 0.219 & 0.11 \\
\hline Urea nitrogen & 0.725 & $<0.001$ \\
\hline $\mathrm{eCrCl}$ & -0.571 & $<0.001$ \\
\hline Cystatin C & 0.767 & $<0.001$ \\
\hline Microalbuminuria & 0.515 & $<0.001$ \\
\hline CRP & 0.133 & 0.33 \\
\hline hs-CRP & 0.123 & 0.37 \\
\hline Interleukin-6 & 0.194 & 0.16 \\
\hline Erythropoietin & -0.395 & 0.003 \\
\hline Transferrin & -0.387 & 0.003 \\
\hline Ferritin & -0.110 & 0.42 \\
\hline TSAT & -0.136 & 0.32 \\
\hline Soluble transferrin receptor & 0.148 & 0.28 \\
\hline $\begin{array}{l}\text { Reticulocyte hemoglobin } \\
\text { content }\end{array}$ & -0.119 & 0.39 \\
\hline Hepcidin-25 & 0.147 & 0.28 \\
\hline \multicolumn{3}{|c|}{$\begin{array}{l}\text { Abbreviations: NGAL, neutrophil gelatinase- } \\
\text { associated lipocalin; NTproBNP, N-terminal } \\
\text { pro-brain natriuretic peptide; eCrCl, } \\
\text { estimated creatinine clearance by Cockroft } \\
\text { Gault; CRP, C-reactive protein; hs-CRP, high } \\
\text { sensitivity CRP; TSAT, transferrin saturation }\end{array}$} \\
\hline
\end{tabular}




\section{Kidney \\ Blood Pressure Research}

Kidney Blood Press Res 2012;36:344-354

\begin{tabular}{l|l}
\hline DOI: $10.1159 / 000343392$ & (C) 2012 S. Karger AG, Basel
\end{tabular}

Published online: December 12, 2012

www.karger.com/kbr

349
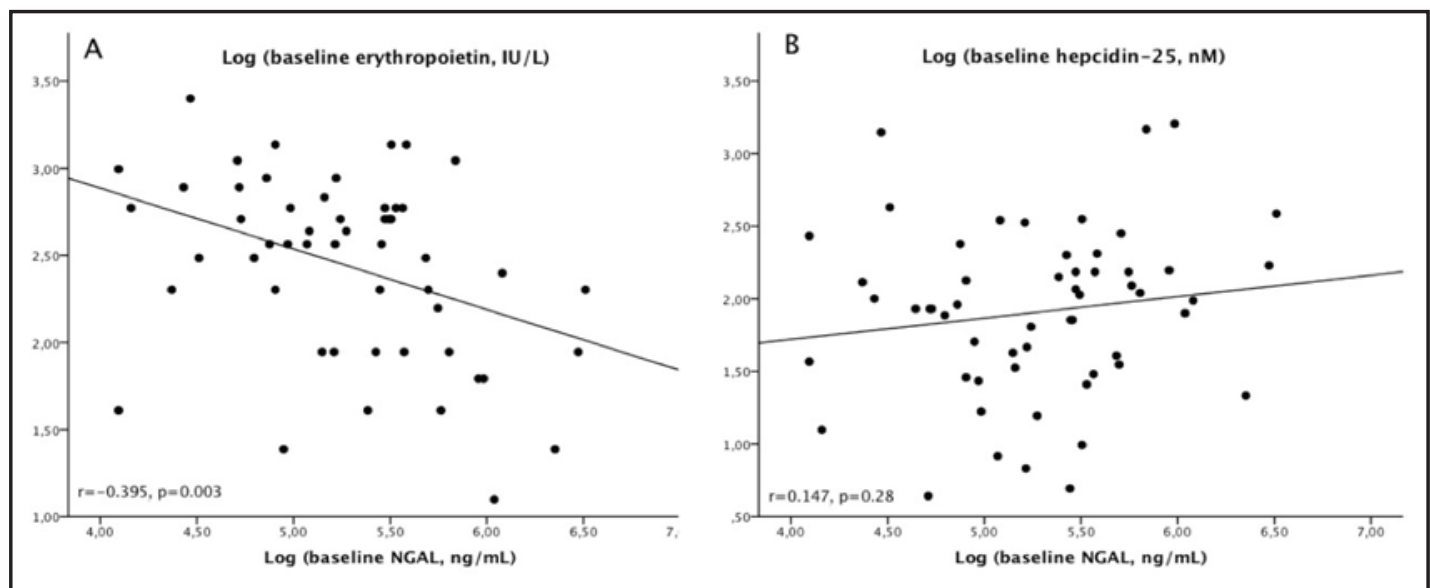

Fig. 1. The correlation between log-transformed baseline serum NGAL levels and baseline log-transformed erythropoietin levels (A) and baseline log-transformed hepcidin-25 levels (B). NGAL levels positively correlate with baseline erythropoietin levels and show no correlation with hepcidin-25 levels. Abbreviations: NGAL, neutrophil gelatinase associated lipocalin.

Table 4: Effects of 2 weeks ESA treatment versus no treatment

\begin{tabular}{lcccccc}
\hline Characteristic & $\mathrm{t}=0$ & $\begin{array}{c}\mathrm{ESA}(\mathrm{n}=37) \\
\mathrm{t}=2 \text { weeks }\end{array}$ & $\mathrm{p}$-value & $\mathrm{t}=0$ & $\begin{array}{c}\text { No ESA (n=19) } \\
\mathrm{t}=2 \text { weeks }\end{array}$ & $\mathrm{p}$-value \\
\hline Hemoglobin (g/dL) & $11.7 \pm 0.95$ & $12.0 \pm 1.12$ & $\mathbf{0 . 0 1 8}$ & $11.8 \pm 0.79$ & $11.7 \pm 0.86$ & 0.50 \\
Reticulocytes (x1012/L) & $0.046 \pm 0.015$ & $0.064 \pm 0.018$ & $<\mathbf{0 . 0 0 1}$ & $0.044 \pm 0.016$ & $0.047 \pm 0.017$ & 0.30 \\
STfR (mg/L) & $1.39 \pm 0.48$ & $1.77 \pm 0.53$ & $<\mathbf{0 . 0 0 1}$ & $1.35 \pm 0.47$ & $1.44 \pm 0.49$ & 0.12 \\
Ret-He (fmol) & $1.90 \pm 0.15$ & $1.82 \pm 0.23$ & 0.24 & $1.88 \pm 0.12$ & $1.84 \pm 0.15$ & 0.30 \\
eCrCl (ml/min) & $35 \pm 12$ & $35 \pm 11$ & 0.40 & $39 \pm 20$ & $39 \pm 18$ & 0.87 \\
Cystatin C (mg/l) & $2.0 \pm 0.83$ & $1.9 \pm 0.76$ & 0.78 & $2.0 \pm 0.77$ & $2.0 \pm 0.72$ & 0.64 \\
hs-CRP (mg/L) & $5.4[1.3-10.9]$ & $2.2[1.1-4.8]$ & 0.08 & $4.3[1.7-6.9]$ & $6.6[2.1-14.2]$ & 0.34 \\
Interleukin-6 (pg/mL) & $3.7[1.8-4.9]$ & $3.7[2.2-5.8]$ & 0.28 & $3.2[2.3-7.0]$ & $3.3[2.0-5.8]$ & 0.93 \\
\hline Mean \pm standard deviation or median [interquartile range] are shown. Abbreviations: sTfR, soluble transferrin receptor; Ret- \\
He, reticulocyte hemoglobin content; eCrCl, estimated creatinine clearance by Cockroft Gault; hs-CRP, high sensitivity CRP; \\
NTproBNP, N-terminal pro-brain natriuretic peptide \\
\hline
\end{tabular}

significantly increased in the ESA group compared to baseline. Individual NGAL levels at baseline and after two weeks are shown in Figure 2. NGAL levels significantly decreased after two weeks in the ESA group $(p=0.02)$ whereas there was no change in the no-ESA group $(\mathrm{p}=0.62)$.

The magnitude of decrease in NGAL levels after two weeks ESA treatment correlated positively with baseline endogenous EPO levels ( $\mathrm{r}=0.431, \mathrm{p}=0.01$, Fig. 3A) and Ret-He $(r=0.396, p=0.02$, Fig. 3B) and negatively with baseline serum NGAL levels $(r=-0.615$, $\mathrm{p}<0.001)$. There was no correlation between the magnitude in decrease in NGAL levels and baseline eCrCl, cystatin $\mathrm{C}$, baseline Hb-levels or the magnitude in increase of reticulocyte count and sTfR.

\section{Response to ESA treatment after 26 weeks}

After two weeks the ESA group split into the ESA-Hb-stable and the ESA-Hb-rise group. Based on the single time point $\mathrm{Hb}$ levels after 26 weeks, the $\mathrm{Hb}$ increased significantly compared to baseline in the ESA-Hb-rise group (resp. $13.3 \pm 1.40$ vs $11.8 \pm 1.08, \mathrm{p}<0.001$ ) and the ESA-Hb-stable group (resp. $12.6 \pm 0.74$ vs $11.7 \pm 0.84 \mathrm{~g} / \mathrm{dL}, \mathrm{p}=0.001$ ). The Hb AUC, depicting the cumulative $\mathrm{Hb}$ change over time and a better reflection of the overall exposure to higher $\mathrm{Hb}$ level than a comparison at 1 time point, was significantly higher in the ESA-Hbrise group compared to the ESA-Hb-stable group (resp. $19.8 \pm 17.2$ vs $5.9 \pm 9.6, p=0.009$ ). 


\section{Kidney \\ Blood Pressure \\ Research}

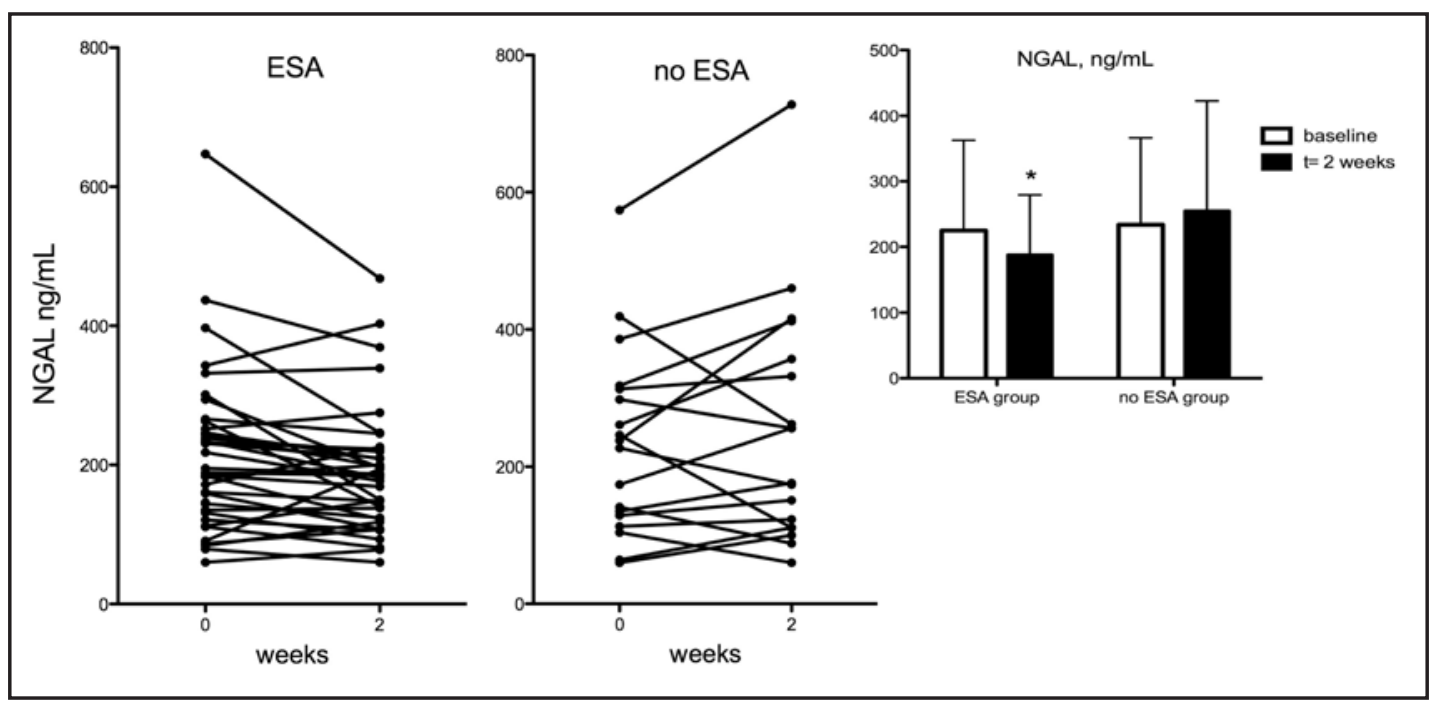

Fig. 2. Serum NGAL levels at baseline and after two weeks of ESA treatment; individual serum NGAL levels at baseline and after two weeks of ESA treatment $(n=37)$ versus no ESA treatment $(n=19)$. Two weeks of ESA treatment decreased log-transformed serum NGAL levels in patients with combined CHF and CKD, as depicted in the bar graph. Abbreviations; NGAL, neutrophil gelatinase associated lipocalin; ESA, erythropoiesis-stimulating agent. Error bars represent SD; * $\mathrm{p}<0.05$.

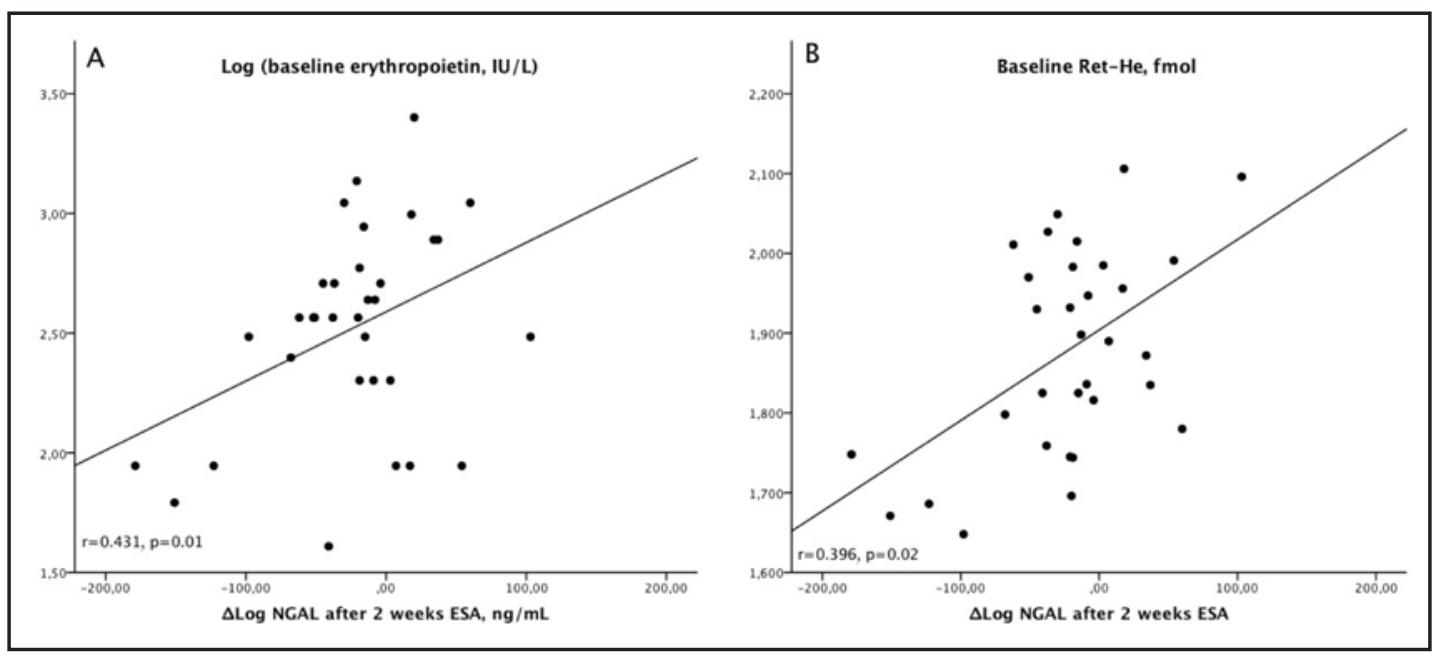

Fig. 3. The correlation between the magnitude in log-transformed serum NGAL decrease after two weeks of ESA treatment and baseline log-transformed erythropoietin levels (A) and baseline reticulocyte hemoglobin content levels (B). Abbreviations: NGAL, neutrophil gelatinase associated lipocalin; ESA, erythropoiesisstimulating agent; Ret-He, reticulocyte hemoglobin content.

Furthermore, the Hb AUC in the control group (-2.2 \pm 9.4$)$ did not differ from the ESA-Hbstable group $(\mathrm{p}=0.99)$.

NGAL values after 26 weeks showed no significant changes compared to baseline levels in all three the study groups (ESA-Hb-rise, 168 [144-259] vs 195 [146-266] ng/mL, $\mathrm{p}=0.27$; ESA-Hb-stable 152 [128-211] vs 187 [126-280] $\mathrm{ng} / \mathrm{mL}, \mathrm{p}=0.97$; control group 244 [115-319] vs 238 [129-313], $p=0.99$ ). Nor were there any significant changes in cystatin $C$ or eCrCl values after 26 weeks compared to baseline (data not shown). 


\section{Kidney \\ Blood Pressure Research}

Kidney Blood Press Res 2012;36:344-354

\begin{tabular}{l|l}
\hline DOI: $10.1159 / 000343392$ & (C) 2012 S. Karger AG, Basel
\end{tabular}

Published online: December 12, 2012

www.karger.com/kbr

\section{Discussion}

The main finding of the present study is that in combined CKD and CHF elevated serum NGAL levels inversely correlate with baseline EPO levels, independent of renal function. Concurrently low dose ESA treatment induced a moderate decrease in serum NGAL levels. However, there was no long-term effect of 26 weeks ESA treatment on NGAL levels. Lastly, although our study confirms that baseline serum NGAL levels are elevated in mildly anemic patients with combined CKD and CHF, NGAL levels did not correlate with parameters of iron metabolism.

Recent reports show that decreased serum NGAL levels in hemodialysis patients correlate with higher (total) hepcidin levels and lower TSAT [11, 12], suggesting that low serum NGAL levels are associated with reduced iron utilization. Both CKD and CHF are chronic inflammatory conditions in which iron metabolism is disturbed. Therefore, we further explored the findings of Bolignano et al [12] and Malyszko et al [11], in a cohort of oral iron supplemented, mildly anemic patients with combined chronic CHF and CKD. In this cohort we found, unexpectedly, no association between serum NGAL levels and parameters for iron availability, as assessed by hepcidin-25 levels (determined by mass spectrometry), reticulocyte hemoglobin content (Ret-He), soluble transferrin receptor (sTfR) and TSAT. In addition, we detected a moderate association between serum NGAL levels and inflammation, as estimated by hs-CRP and IL-6, However, it should be noted that the median hs-CRP levels in this stable, low-inflammatory cohort were only mildly elevated.

An important finding of our study is that serum NGAL levels inversely correlated with endogenous EPO levels, independent of renal function, and that NGAL levels, contrary to our hypothesis, acutely decreased in response to low-dose ESA treatment, albeit that the response was modest and variable. To our knowledge, this is the first study that demonstrates an effect of low-dose ESA treatment on serum NGAL levels. A stronger decrease in NGAL levels correlated with higher baseline EPO levels and Ret-He. However, this effect was no longer present after 6 months treatment, regardless of maintained Hb-levels by phlebotomies or increased Hb-levels.

It is unlikely that in our study NGAL levels reflected iron metabolism as baseline NGAL levels and the ESA induced decrease in NGAL were not associated with markers of iron metabolism such as hepcidin-25. A possible explanation for our findings is that in our population serum NGAL is a marker of on-going tubular damage. This finding is in agreement with studies showing that NGAL predominantly reflects tubular damage in acute conditions $[25,26]$. A comparable association was already explored about ten years ago for IgA nephropathy; urinary $\mathrm{N}$-acetyl- $\beta$-D-glucosaminidase (NAG), a marker of tubular injury, correlated with EPO levels [27]. Also, several animal studies show a direct cytoprotective effect of ESA on intrinsic renal cells $[28,29]$. In a rat model of ischemic injury, low doses of darbepoietin, not resulting in increases in hematocrit levels, significantly reduced glomerulosclerosis and tubulointerstitial damage, and rarefaction of peritubular capillaries was prevented [28]. It should be pointed out that, although initial studies suggested a beneficial effect of fix-dose ESA administration on renal function [28, 30], this was not confirmed in later studies that used variable doses of ESA to reach preset hemoglobin targets $[31,32]$. However, in order to corroborate a role for NGAL as tubular marker in our study, urinary NGAL levels and other urinary markers should be performed, which was not the case in this study [33].

The present study admittedly has some limitations. First, the study size is relatively small which is due to the complexity of the study design. Studying univariate correlations is of limited value is a small cohort. However, we believe that the lack of association between serum NGAL levels and iron metabolism is unambiguous, due to its assessment by multiple parameters for iron metabolism, including hepcidin-25 levels. However, we cannot exclude the possibility that the lack of univariate association between NGAL and inflammation is due to lack of power. 


\section{Kidney \\ Blood Pressure Research}

Kidney Blood Press Res 2012;36:344-354

\begin{tabular}{l|l}
\hline DOI: $10.1159 / 000343392$ & C 2012 S. Karger AG, Basel
\end{tabular}

Published online: December 12, 2012

www.karger.com/kbr

Emans/Braam/Diepenbroek/van der Putten/Cramer/Wielders/Swinkels/Doevendans/ Gaillard: NGAL Decreases in Response to ESA in Chronic Cardiorenal Failure

\section{Conclusions}

Serum NGAL levels in combined CHF/CKD do not reflect iron homeostasis, as assessed by hepcidin-25 levels, Ret-He, sTfR and TSAT and therefore may reflect the tubular damage. Short-term low-dose ESA treatment discreetly decreases serum NGAL levels, which might possibly reflect an effect of ESA on tubular damage. Furthermore, baseline EPO levels correlate with serum NGAL levels, independent of eCrCl or Hb-levels. Further research is required to investigate these acute effects of low-dose ESA treatment on serum NGAL levels in CHF, CKD or the combination of both.

\section{Conflict of Interest}

The authors of this manuscript state that they have no conflicts of interest.

\section{Acknowledgements}

This investigator-initiated study was supported by the Netherlands Heart Foundation (grant number 2005B192) and by an unrestricted grant from Roche Pharmaceuticals, the Netherlands. Alere inc. (San Diego, CA, USA) supported this study by supplying the use of the Triage ${ }^{\circledR}$ Meter and the required Triage ${ }^{\circledR}$ Tests. This is an investigatorinitiated study and no changes to the study protocol were made upon request of Roche or Alere ${ }^{\circledR}$. Heart and Stroke Foundation of Canada New Investigator award supports Branko Braam.

\section{References}

1 Mori K, Lee HT, Rapoport D, Drexler IR, Foster K, Yang J, Schmidt-Ott KM, Chen X, Li JY, Weiss S, Mishra J, Cheema FH, Markowitz G, Suganami T, Sawai K, Mukoyama M, Kunis C, D'Agati V, Devarajan P, Barasch J: Endocytic delivery of lipocalin-siderophore-iron complex rescues the kidney from ischemia-reperfusion injury. J Clin Invest 2005;115:610-621.

-2 Schilcher G, Ribitsch W, Otto R, Portugaller RH, Quehenberger F, Truschnig-Wilders M, Zweiker R, Stiegler P, Brodmann M, Weinhandl K, Horina JH: Early detection and intervention using neutrophil gelatinaseassociated lipocalin (ngal) may improve renal outcome of acute contrast media induced nephropathy: A randomized controlled trial in patients undergoing intra-arterial angiography (anti-cin study). BMC Nephrol 2011;12:39.

3 Bolignano D, Donato V, Coppolino G, Campo S, Buemi A, Lacquaniti A, Buemi M: Neutrophil gelatinaseassociated lipocalin (ngal) as a marker of kidney damage. Am J Kidney Dis 2008;52:595-605.

4 Dent CL, Ma Q, Dastrala S, Bennett M, Mitsnefes MM, Barasch J, Devarajan P: Plasma neutrophil gelatinaseassociated lipocalin predicts acute kidney injury, morbidity and mortality after pediatric cardiac surgery: A prospective uncontrolled cohort study. Crit Care 2007;11:R127.

5 Bolignano D, Lacquaniti A, Coppolino G, Campo S, Arena A, Buemi M: Neutrophil gelatinase-associated lipocalin reflects the severity of renal impairment in subjects affected by chronic kidney disease. Kidney Blood Press Res 2008;31:255-258.

6 Poniatowski B, Malyszko J, Bachorzewska-Gajewska H, Malyszko JS, Dobrzycki S: Serum neutrophil gelatinase-associated lipocalin as a marker of renal function in patients with chronic heart failure and coronary artery disease. Kidney Blood Press Res 2009;32:77-80.

7 Jungbauer CG, Birner C, Jung B, Buchner S, Lubnow M, von Bary C, Endemann D, Banas B, Mack M, Boger CA, Riegger G, Luchner A: Kidney injury molecule-1 and n-acetyl-ss-d-glucosaminidase in chronic heart failure: Possible biomarkers of cardiorenal syndrome. Eur J Heart Failure 2011;13:1104-1110. 


\section{Kidney \\ Blood Pressure Research}

8 Damman K, Masson S, Hillege HL, Maggioni AP, Voors AA, Opasich C, van Veldhuisen DJ, Montagna L, Cosmi F, Tognoni G, Tavazzi L, Latini R: Clinical outcome of renal tubular damage in chronic heart failure. Eur Heart J 2011;32:2705-2712.

-9 Maisel AS, Mueller C, Fitzgerald R, Brikhan R, Hiestand BC, Iqbal N, Clopton P, van Veldhuisen DJ: Prognostic utility of plasma neutrophil gelatinase-associated lipocalin in patients with acute heart failure: The ngal evaluation along with b-type natriuretic peptide in acutely decompensated heart failure (gallant) trial. Eur J Heart Failure 2011;13:846-851.

10 Yang J, Goetz D, Li JY, Wang W, Mori K, Setlik D, Du T, Erdjument-Bromage H, Tempst P, Strong R, Barasch J: An iron delivery pathway mediated by a lipocalin. Mol Cell 2002;10:1045-1056.

11 Malyszko J, Malyszko JS, Kozminski P, Koc-Zorawska E, Mysliwiec M, Macdougall I: Possible relationship between neutrophil gelatinase-associated lipocalin, hepcidin, and inflammation in haemodialysed patients. Nephron Clin Practice 2010;115:c268-c275.

12 Bolignano D, Coppolino G, Romeo A, De Paola L, Buemi A, Lacquaniti A, Nicocia G, Lombardi L, Buemi M: Neutrophil gelatinase-associated lipocalin (ngal) reflects iron status in haemodialysis patients. Nephrol Dial Transplant 2009;24:3398-3403.

13 Malyszko J, Tesar V, Macdougall IC: Neutrophil gelatinase-associated lipocalin and hepcidin: What do they have in common and is there a potential interaction? Kidney Blood Press Res 2010;33:157-165.

14 Okonko DO, Mandal AK, Missouris CG, Poole-Wilson PA: Disordered iron homeostasis in chronic heart failure: Prevalence, predictors, and relation to anemia, exercise capacity, and survival. J Am Coll Cardiol 2011;58:1241-1251.

15 Jankowska EA, Rozentryt P, Witkowska A, Nowak J, Hartmann O, Ponikowska B, Borodulin-Nadzieja L, Banasiak W, Polonski L, Filippatos G, McMurray JJV, Anker SD, Ponikowski P: Iron deficiency: An ominous sign in patients with systolic chronic heart failure. Eur Heart J 2010;31:1872-1880.

-16 van der Putten K, Jie KE, van den Broek D, Kraaijenhagen RJ, Laarakkers C, Swinkels DW, Braam B, Gaillard CA: Hepcidin-25 is a marker of the response rather than resistance to exogenous erythropoietin in chronic kidney disease/chronic heart failure patients. Eur J Heart Fail 2010;12:943-950.

17 Kroot JJ, Tjalsma H, Fleming RE, Swinkels DW: Hepcidin in human iron disorders: Diagnostic implications. Clin Chem 2011;57:1650-1669.

-18 van der Putten K, Jie KE, Emans ME, Verhaar MC, Joles JA, Cramer MJ, Velthuis BK, Meiss L, Kraaijenhagen RJ, Doevendans PA, Braam B, Gaillard CA: Erythropoietin treatment in patients with combined heart and renal failure: Objectives and design of the epocares study. J Nephrol 2010;23:363-368.

19 Dickstein K, Cohen-Solal A, Filippatos G, McMurray JJ, Ponikowski P, Poole-Wilson PA, Stromberg A, van Veldhuisen DJ, Atar D, Hoes AW, Keren A, Mebazaa A, Nieminen M, Priori SG, Swedberg K, Vahanian A, Camm J, De Caterina R, Dean V, Dickstein K, Filippatos G, Funck-Brentano C, Hellemans I, Kristensen SD, McGregor K, Sechtem U, Silber S, Tendera M, Widimsky P, Zamorano JL, Tendera M, Auricchio A, Bax J, Bohm M, Corra U, della Bella P, Elliott PM, Follath F, Gheorghiade M, Hasin Y, Hernborg A, Jaarsma T, Komajda M, Kornowski R, Piepoli M, Prendergast B, Tavazzi L, Vachiery JL, Verheugt FW, Zamorano JL, Zannad F: Esc guidelines for the diagnosis and treatment of acute and chronic heart failure 2008: The task force for the diagnosis and treatment of acute and chronic heart failure 2008 of the european society of cardiology. Developed in collaboration with the heart failure association of the esc (hfa) and endorsed by the european society of intensive care medicine (esicm). Eur J Heart Fail 2008;10:933-989.

20 Paulus WJ, Tschope C, Sanderson JE, Rusconi C, Flachskampf FA, Rademakers FE, Marino P, Smiseth OA, De Keulenaer G, Leite-Moreira AF, Borbely A, Edes I, Handoko ML, Heymans S, Pezzali N, Pieske B, Dickstein K, Fraser AG, Brutsaert DL: How to diagnose diastolic heart failure: A consensus statement on the diagnosis of heart failure with normal left ventricular ejection fraction by the heart failure and echocardiography associations of the european society of cardiology. Eur Heart J 2007;28:2539-2550.

-21 Kroot JJC, Laarakkers CMM, Geurts-Moespot AJ, Grebenchtchikov N, Pickkers P, van Ede AE, Peters HPE, van Dongen-Lases E, Wetzels JFM, Sweep FCGJ, Tjalsma H, Swinkels DW: Immunochemical and massspectrometry-based serum hepcidin assays for iron metabolism disorders. Clin Chem 2010;56:1570-1579.

-22 Swinkels DW, Girelli D, Laarakkers C, Kroot J, Campostrini N, Kemna EH, Tjalsma H: Advances in quantitative hepcidin measurements by time-of-flight mass spectrometry. PLoS One 2008;3:e2706.

23 Galesloot TE, Vermeulen SH, Geurts-Moespot AJ, Klaver SM, Kroot JJ, van Tienoven D, Wetzels JF, Kiemeney LA, Sweep FC, den Heijer M, Swinkels DW: Serum hepcidin: Reference ranges and biochemical correlates in the general population. Blood 2011;117:e218-225. 


\section{Kidney \\ Blood Pressure Research}

Kidney Blood Press Res 2012;36:344-354

DOI: 10.1159/000343392

Published online: December 12, 2012

(C) 2012 S. Karger AG, Basel

www.karger.com/kbr

Emans/Braam/Diepenbroek/van der Putten/Cramer/Wielders/Swinkels/Doevendans/ Gaillard: NGAL Decreases in Response to ESA in Chronic Cardiorenal Failure

-24 Duh MS, Lefebvre P, Fastenau J, Piech CT, Waltzman RJ: Assessing the clinical benefits of erythropoietic agents using area under the hemoglobin change curve. Oncologist 2005;10:438-448.

25 Singer E, Elger A, Elitok S, Kettritz R, Nickolas TL, Barasch J, Luft FC, Schmidt-Ott KM: Urinary neutrophil gelatinase-associated lipocalin distinguishes pre-renal from intrinsic renal failure and predicts outcomes. Kidney Int 2011;80:405-414.

-26 Han M, Li Y, Liu M, Cong B: Renal neutrophil gelatinase associated lipocalin expression in lipopolysaccharide-induced acute kidney injury in the rat. BMC Nephrol 2012;13:25.

-27 Machiguchi T, Yoshida H, Yonemoto S, Minakata T, Nomura K, Muso E, Tamura T, Sasayama S: Does circulating erythropoietin reflect progression of iga nephropathy? Comparison with urinary n-acetyl-betad-glucosaminidase. Nephrol Dial Transplant 1999;14:635-640.

-28 Bahlmann FH, Song R, Boehm SM, Mengel M, von Wasielewski R, Lindschau C, Kirsch T, de Groot K, Laudeley R, Niemczyk E, Guler F, Menne J, Haller H, Fliser D: Low-dose therapy with the long-acting erythropoietin analogue darbepoetin alpha persistently activates endothelial akt and attenuates progressive organ failure. Circulation 2004;110:1006-1012.

29 Menne J, Park JK, Shushakova N, Mengel M, Meier M, Fliser D: The continuous erythropoietin receptor activator affects different pathways of diabetic renal injury. J Am Soc Nephrol 2007;18:2046-2053.

30 Gouva C, Nikolopoulos P, Ioannidis JP, Siamopoulos KC: Treating anemia early in renal failure patients slows the decline of renal function: A randomized controlled trial. Kidney Int 2004;66:753-760.

-31 Singh AK, Szczech L, Tang KL, Barnhart H, Sapp S, Wolfson M, Reddan D: Correction of anemia with epoetin alfa in chronic kidney disease. N Engl J Med 2006;355:2085-2098.

-32 Drueke TB, Locatelli F, Clyne N, Eckardt KU, Macdougall IC, Tsakiris D, Burger HU, Scherhag A: Normalization of hemoglobin level in patients with chronic kidney disease and anemia. N Engl J Med 2006;355:2071-2084.

33 Schmidt-Ott KM, Mori K, Li JY, Kalandadze A, Cohen DJ, Devarajan P, Barasch J: Dual action of neutrophil -gelatinase-associated lipocalin. J Am Soc Nephrol 2007;18:407-413. 